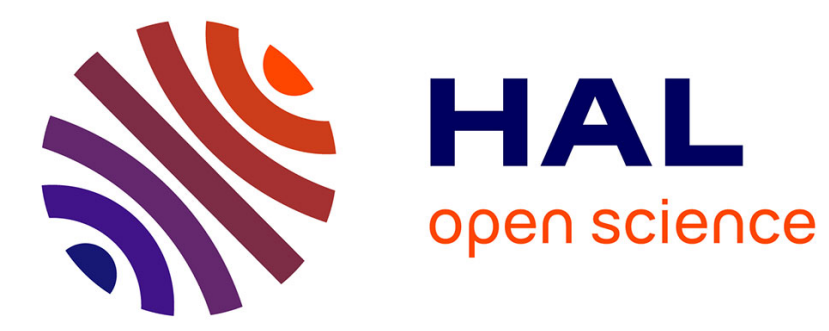

\title{
Study on Precision Fertilization Model Based on Fusion Algorithm of Cluster and RBF Neural Network
}

\author{
Shan Zhao, Guifen Chen, Siwei Fu, Enze Xiao
}

\section{To cite this version:}

Shan Zhao, Guifen Chen, Siwei Fu, Enze Xiao. Study on Precision Fertilization Model Based on Fusion Algorithm of Cluster and RBF Neural Network. 11th International Conference on Computer and Computing Technologies in Agriculture (CCTA), Aug 2017, Jilin, China. pp.56-66, 10.1007/9783-030-06179-1_6. hal-02111507

\section{HAL Id: hal-02111507 https://hal.inria.fr/hal-02111507}

Submitted on 26 Apr 2019

HAL is a multi-disciplinary open access archive for the deposit and dissemination of scientific research documents, whether they are published or not. The documents may come from teaching and research institutions in France or abroad, or from public or private research centers.
L'archive ouverte pluridisciplinaire HAL, est destinée au dépôt et à la diffusion de documents scientifiques de niveau recherche, publiés ou non, émanant des établissements d'enseignement et de recherche français ou étrangers, des laboratoires publics ou privés. 


\title{
Study on Precision Fertilization Model Based on Fusion
}

\section{Algorithm of Cluster and RBF Neural Network}

\author{
Shan Zhao, Guifen Chen ${ }^{(\varpi)}$, Siwei,Fu, Enze Xiao \\ CLC number: TP393 Document code: A
}

College of Information and Technology Science, Jilin Agricultural University, Changchun, Jilin 130118

\begin{abstract}
Precision fertilization is the core content of precision agriculture technology, There was a complex non-linear relationship between crop optimal fertilization and soil fertility, The single model is difficult to accurately describe its complex relationship and change law, making the crop accurate fertilizer is difficult to determine; Neural network technology to solve this problem provides a new way of thinking, But a single radial basis function network (RBF) neural network fertilization model is too dependent on the selection of the hidden layer data center, Therefore, this paper proposes a decision-making technique based on fuzzy C-means (FCM) clustering and RBF neural network fusion algorithm. The fusion algorithm first uses the FCM algorithm to select multiple RBF networks in the training samples. Based on this, the least squares (OLS) training network is used to optimize the data center, Finally, an improved RBF neural network model is established. In this paper, the model is applied to the maize precision operation demonstration base, soil nutrient and maize yield as the the input of neural network, using the precision fertilization amount of maize as output, The model of precision fertilization of maize was established, And the model was used to make the precision fertilization decision of maize. Experimental results show: The improved RBF neural network is compared with the traditional BP network to reduce the error by 0.47 , Compared with the model, the error of the RBF neural network method is reduced by 0.045 , Significantly improve the prediction accuracy, reduce the calculation time, Can effectively guide the precise fertilization.
\end{abstract}

Keywords: fusion optimization algorithm; FCM; OLS; RBF; precision fertilization model

\section{Introduction}

Maize production in Jilin Province, agricultural production occupies an extremely important position, is the largest planting area in Jilin Province, food crops, production accounted for $12.5 \%$ of the country, to 27.88 million t. corn production of Jilin Province is essential to China's food security. Reasonable application of chemical fertilizers is one of the important guarantees of high and stable yield of maize. According to the soil type, soil fertility and maize fertilizer characteristics to fertilize scientifically and reasonably is particularly important. Variable fertilization technology is an important part of precision agriculture, It is based on the actual needs of crops, based on scientific fertilization methods, Identify variables inputs on crop To a certain extent, increased corn production. In the case of reasonable control of the amount of fertilizer, you can achieve both the purpose of reducing investment and increase production. Because of the high nonlinearity between yield and soil nutrient and fertilization, neural network is considered to be a powerful tool to solve nonlinear problems, Therefore, a number of different forms of neural networks are used for precise fertilization decisions. In 2001, Pokrajac et al. Presented a neural network-based decision support system to provide precise fertilization recommendations; In 2002, Teng Qingfang and others tried to use the neural network to establish the soil fertilization model; In 2004, Ma Weilin et al. Proposed a method of variable fertilization decision-making based on data envelopment analysis and artificial neural network. In 2007, Lan Weijuan et al. Applied radial basis function network to variable fertilization decision. The use of RBF network to study the variable fertilization decision has the advantages of simple structure, rapid training process and good promotion ability. It is superior to the BP

ShanZhao (1995-),College of Information Technology, Jilin Agricultural University,ChangChun,China Guifen Chen(1956-), College of Information Technology, Jilin Agricultural University,ChangChun,China 
network in terms of approaching ability and learning speed, and can simplify the structure and learning rules of the network. Therefore, this paper uses FCM algorithm and OLS fusion algorithm to optimize RBF neural network, and constructs a RBF neural network prediction model based on fusion algorithm, To adapt the content of soil nutrients, fertilizer and food production randomness, complexity and nonlinear variation, Through the different soil types and yield prediction fertilization, to explore the realization of high yield of corn nitrogen, phosphorus, potassium fertilizer the best amount of application, For the rational use of fertilizer on the production, improve fertilizer utilization to provide a reference. To guide the variable fertilization in production of maize in central Jilin Province, in order to improve food productivity, to achieve sustainable development of productivity.

\section{Technology and methods}

Techniques employed herein route is divided into three parts: first, Normalizing treatment the Data samples, and using the FCM algorithm select primary data center; the second usage OLS to train RBF neural network to generate a regression matrix, preferably the data center; Thirdly, using the RBF neural network to construct the precision fertilization model. The specific description shown in Figure 1:

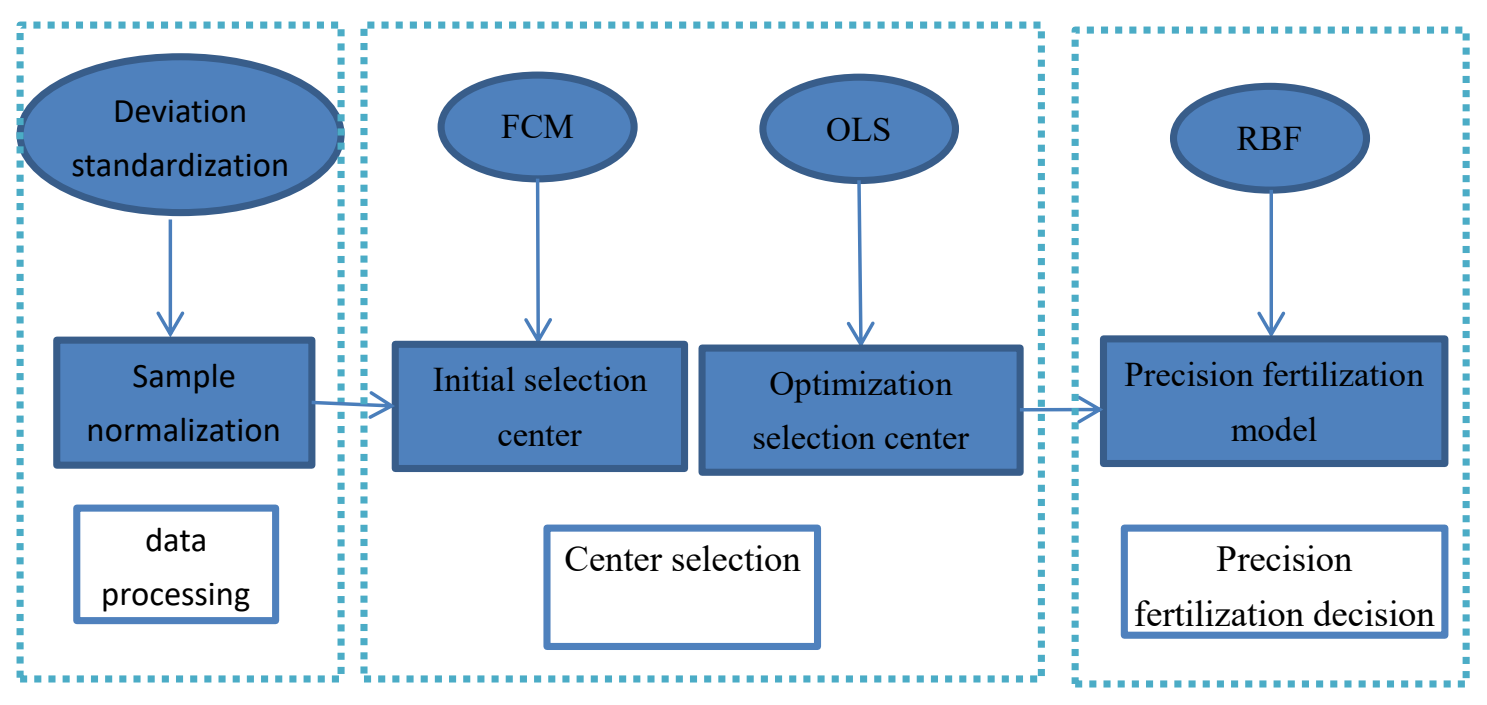

Figure 1: the technical roadmap for this article

\subsection{RBF neural network prediction algorithm}

The RBF (Radial Basis Function) neural network model was proposed by Moody and Darken in 1988, it is a three-layer feedforward neural network, the first layer is the input layer, composed of the source node; the second layer for the hidden layer, the activation function using radial basis function (this article is Gaussian function),and Usually defined as any data sample to a data center Euclidean distance between the monotonic function; The third layer is the output layer, the hidden layer to the output layer using linear activation function. In this paper, four factors affecting the amount of maize fertilizer were obtained, so the input vector $\mathrm{n}=4$, $\mathrm{h}$ hidden layer, $\mathrm{m}$ output vector is the amount of soil fertilization of Alkaline $\mathrm{N}(\mathrm{N})$ Available phosphorus (P) Available potassium (K).so $\mathrm{m}=3$ 


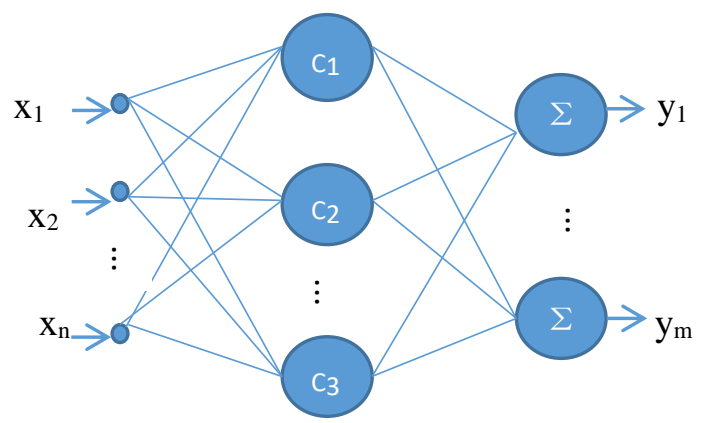

Figure 2:RBF network structure

By RBFNN learning process and its network mapping relationship, RBF performance depends on the strong choice of the center number, the center value and its location. Therefore, if all the input as a candidate space, it will bring a very large amount of calculation, reducing network performance. In order to overcome this deficiency, FCM algorithm can be used to narrow the candidate space and reduce the network size to improve the computational efficiency.

\subsection{FCM clustering algorithm primary network center}

Fuzzy C-means (FCM) is proposed by Bezdek et al. FCM compared with the traditional clustering analysis algorithm,It introduced The fuzzy mathematics theory, which is an unsupervised clustering algorithm based on objective function. Corn soil nutrient, yield and fertilizer data samples usually have serious non-linear characteristics, Single model is difficult to describe, so it is necessary to divide the data sample set into different subclasses. The In order to reduce the number of RBFNN centers, FCM clustering is used to initialize the sample training set.And can improve the speed of network computing efficiency, so that the forecast is more accurate.

The basic idea of FCM is to divide all data samples into c fuzzy groups, The cluster center of each fuzzy group is determined by minimizing the objective function value. And the degree of membership in the $[0,1]$ is used to determine the degree to which each given data belongs to each fuzzy group. Its membership matrix U must satisfy equation (1):

$$
\sum_{i=1}^{c} u_{i j}=1, \forall j=1, \ldots, n
$$

The objective function of FCM algorithm is generally as follows: (2):

$$
J\left(U, c_{1}, \ldots, c_{c}\right)=\sum_{i=1}^{c} J_{i}=\sum_{i=1}^{c} \sum_{j}^{n} u_{i j}^{k} d_{i j}^{2}
$$

In the formula, $\mathrm{u}_{\mathrm{ij}}$ Is the degree of membership; $\mathrm{d}_{\mathrm{ij}}=\left\|\mathrm{c}_{\mathrm{i}}-\mathrm{x}_{\mathrm{j}}\right\|$ Represents the Euclidean distance between the $\mathrm{i}$-th cluster center and the $\mathrm{j}$-th data point; $c i$ is the clustering center of each fuzzy group; $k \in[1, \infty)$ Is a weighted power exponent. In order to achieve the minimum target function, We introduce the Lagrangian multiplier $\lambda_{\mathrm{j}}(\mathrm{j}=[1, \mathrm{n}])$ The constructor is shown in Equation 3:

$$
J\left(U, c_{i}, \ldots, c_{c}, \lambda_{n}\right)=J\left(U, c_{1}, \ldots, c_{c}\right)+\sum_{j=1}^{n} \lambda_{j}\left(\sum_{i=1}^{c} u_{i j}-1\right)=\sum_{i=1}^{c} \sum_{j}^{n} u_{i j}^{k} d_{i j}^{2}+\sum_{i=1}^{n} \lambda_{j}\left(\sum_{i=1}^{c} u_{i j}-1\right)
$$

Derivating the parameters for each parameter, the requirement of Making Formula 3 Minimal is

$$
\mathrm{c}_{i}=\frac{\sum_{j=1}^{n} u_{i j}^{k} x_{j}}{\sum_{i=1}^{n} u_{i j}^{k}}
$$




$$
\mathrm{u}_{\mathrm{ij}}=\frac{1}{\sum_{k=1}^{c}\left(\frac{d_{i j}}{d_{k j}}\right)^{2 /(k-1)}}
$$

The specific FCM algorithm steps are as follows:

Step 1: Given the clustering category c, $2 \leq \mathrm{c} \leq \mathrm{N}, \mathrm{N}$ is the number of initial data samples, Initial membership matrix is $U(0)$, And set the threshold $\varepsilon$;

Step 2: initialize the cluster center $c_{i}(t), i=1,2, \ldots, n$;

Step 2: calculate the membership degree $u_{i j}(t)$ with the formula $(5), i=1,2, \ldots, c ; j=1,2, \ldots, n$;

Step 4: Use the obtained membership degree to correct the cluster center $c_{i}(t+1), i=1,2, \ldots, c$ according to (4);

Step 5: Calculate the error $\mathrm{e}=\sum_{\mathrm{i}=1}^{\mathrm{c}}\left\|c_{i}(t+1)-c_{i}(t)\right\|^{2} \quad$ If $\mathrm{e}<\mathrm{E}_{\max }$ the operation is over, otherwise let $\mathrm{t}+1=\mathrm{t}$, return to the third step.

\subsection{Orthogonal least squares optimization center}

RBF network center selection orthogonal least squares (orthogoral least squares algorithm OLS) algorithm, Which solves the key problems in the construction of radial basis function network. OLS algorithm uses the orthogonalization method to independently calculate the contribution of the regression operator to the output, so the center selection step is simple and effective. OLS algorithm is the basic idea: The center of the radial basis function is chosen as a subset of the training pattern, Choose one sample at a time, Through the orthogonal regression matrix, the regression operator with large error compression ratio is selected, And the number of regression operators is determined by the selected tolerance, And then find the network weight. The RBF neural network is trained with OLS, and the matrix representation of the expected output response is:

$$
Y=\hat{Y}+E=\phi W+E
$$

Where $\mathrm{Y} \in \mathrm{R}^{\mathrm{n} * 3}$ is the desired output matrix; $\widehat{\mathrm{Y}} \in \mathrm{R}^{\mathrm{n} * 3}$ is the output matrix of the neural network model; $\Phi \in \mathrm{R}^{\mathrm{n} * \mathrm{~h}}$ is the regression matrix; $\mathrm{E} \in \mathrm{R}^{\mathrm{n} * 3}$ is the output error matrix. In this paper, Schmidt orthogonalization method to reduce the output error. OLS algorithm can save storage space and improve operation efficiency, and is very suitable for training RBF network. The RBF neural network trained by OLS can obtain a more optimized data center, improve the accuracy of the network, greatly reduce the computational complexity of the network and improve the training speed.

\section{Application of RBF Neural Network Fusion Algorithm in Precision}

\section{Fertilization Decision of Maize}

\subsection{Experimental data}

Experimental data from the "National Spark Program" in Jilin Province, Nong'an County, Helong Town, Chen Jiadian Village and Kai'an town experimental field. In order to achieve accurate fertilization, the grid was divided into grid, the grid size is $40 \mathrm{~m} \times 40 \mathrm{~m}$. Figure 2 is Chenjiadian village and Kai'an town experimental field grid. 


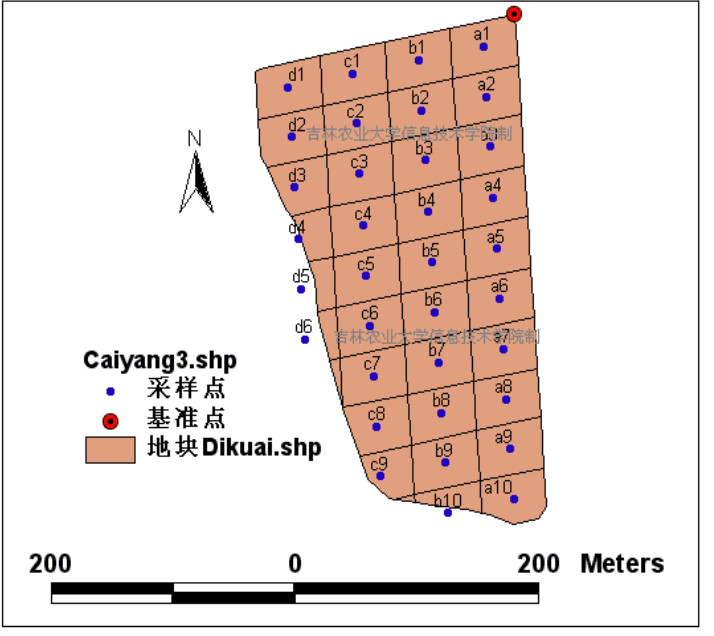

(a) Chen Jiadian village plot grid

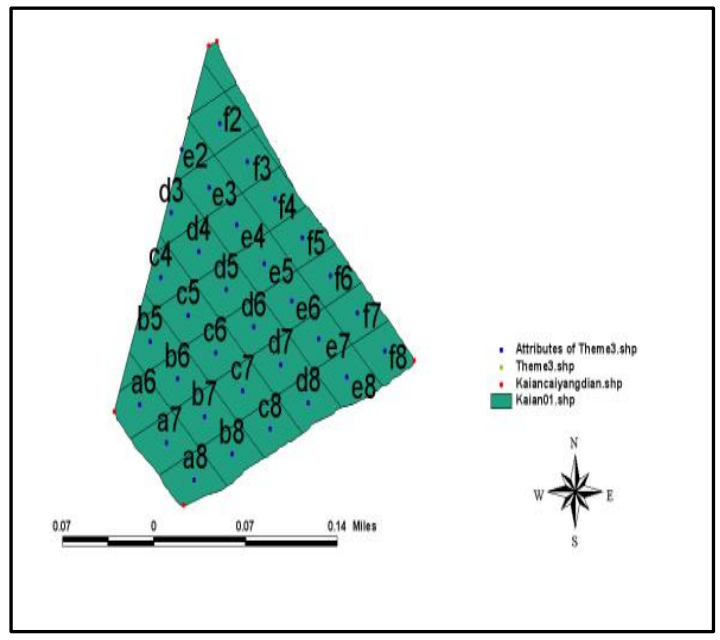

(b)The kaian town grid diagram

Figure 3: Experimental area grid

In the year of 2015, the experimental field was tested, fertilized and tested, and finally 64 samples were obtained. Each sample consisted of seven attributes: soil N, P, K content, actual yield, N, P, K fertilizer The amount of application, part of the experimental data shown in Table 1 and Table 2:

Table 1: Chenjiadian Village Experimental Field

\begin{tabular}{|c|c|c|c|c|c|c|c|}
\hline Plots & $\begin{array}{l}\mathrm{N} \\
\text { conten }\end{array}$ & $\begin{array}{l}\mathrm{P} \\
\text { content }\end{array}$ & K & $\mathrm{N}$ & P & $\mathrm{K}$ & $\begin{array}{l}\text { Measured } \\
\text { yield }\end{array}$ \\
\hline & $\mathrm{tmg} / \mathrm{kg}$ & $\mathrm{mg} / \mathrm{kg}$ & & $\mathrm{kg} / \mathrm{hm}$ & & $\mathrm{kg} / \mathrm{hm}$ & $\mathrm{kg} / \mathrm{hm}$ \\
\hline a1 & 115 & 14.8 & 159 & 75.6 & 32.3 & 64.8 & 8303 \\
\hline $\mathrm{a} 2$ & 115 & 14.8 & 159 & 75.6 & 32.3 & 66.1 & 8470 \\
\hline a3 & 136 & 17.55 & 159 & 76.9 & 31.4 & 66.8 & 8556 \\
\hline $\mathrm{a} 4$ & 136 & 17.55 & 159 & 76.9 & 31.4 & 66.1 & 8461 \\
\hline a5 & 133 & 14.6 & 182 & 76.7 & 32.4 & 66.3 & 8684 \\
\hline a6 & 133 & 14.6 & 182 & 76.7 & 32.4 & 56.2 & 7367 \\
\hline a7 & 129 & 17.55 & 182 & 76.5 & 31.4 & 61.1 & 8002 \\
\hline a8 & 129 & 17.55 & 182 & 76.5 & 31.4 & 65.4 & 8564 \\
\hline a9 & 118 & 16.3 & 165 & 75.3 & 32.3 & 60.1 & 7745 \\
\hline a10 & 125 & 15.8 & 179 & 77.1 & 32.3 & 62.7 & 8192 \\
\hline
\end{tabular}

Table 2: Kai'an Town Experimental Field

\begin{tabular}{|c|c|c|c|c|c|c|c|}
\hline Plots & $\begin{array}{l}\mathrm{N} \\
\text { conten }\end{array}$ & $\begin{array}{l}\mathrm{P} \\
\text { content }\end{array}$ & $\begin{array}{l}\mathrm{K} \\
\text { content }\end{array}$ & $\begin{array}{l}\mathrm{N} \\
\text { amount }\end{array}$ & $\begin{array}{l}\mathrm{P} \\
\text { amount }\end{array}$ & $\begin{array}{l}\mathrm{K} \\
\text { amount }\end{array}$ & $\begin{array}{l}\text { Measured } \\
\text { yield }\end{array}$ \\
\hline & $\mathrm{tmg} / \mathrm{kg}$ & $\mathrm{mg} / \mathrm{kg}$ & $\mathrm{mg} / \mathrm{kg}$ & $\mathrm{kg} / \mathrm{hm}$ & $\mathrm{kg} / \mathrm{hm}$ & $\mathrm{kg} / \mathrm{hm}$ & $\mathrm{kg} / \mathrm{hm}$ \\
\hline a6 & 133 & 26.7 & 240 & 76.7 & 28.80 & 70.0 & 7696.5 \\
\hline a7 & 108.5 & 38.6 & 270 & 75.2 & 26.20 & 61.6 & 7592.25 \\
\hline a8 & 161 & 30.3 & 180 & 78.7 & 27.96 & 72.2 & 8180.25 \\
\hline b5 & 108.5 & 35.8 & 230 & 75.2 & 26.76 & 65.7 & 7805.25 \\
\hline b6 & 101.5 & 35.2 & 230 & 74.8 & 26.89 & 66.0 & 8817 \\
\hline b7 & 140 & 30.7 & 160 & 77.2 & 27.87 & 73.4 & 7587.75 \\
\hline b8 & 175 & 36.2 & 200 & 79.8 & 26.68 & 67.5 & 7221.75 \\
\hline $\mathrm{c} 4$ & 98 & 21.4 & 220 & 74.6 & 30.22 & 74.9 & 6804 \\
\hline$c 5$ & 112 & 32.45 & 280 & 75.4 & 27.46 & 63.9 & 7360.5 \\
\hline c6 & 168 & 33.2 & 240 & 79.2 & 27.31 & 66.3 & 7576.5 \\
\hline
\end{tabular}


In the process of network model training will appear a larger input variable to suppress the phenomenon of smaller input variables, resulting in increased network training time, and even the network can not converge. If the data dimension is inconsistent, it is easy to cause the sickness of the model. In order to remove the data in the dimension and the order of magnitude to establish the impact of network accuracy, After obtaining the sample vector, this paper takes the normalization of the data samples to deal with, namely:

$$
x_{p i}^{\prime}=\frac{x_{p i}-\min \left\{x_{i}\right\}}{\max \left\{x_{i}\right\}-\min \left\{x_{i}\right\}}
$$

In the formula: $X_{p i}$ is the raw data of the $i$-th variable of the pth sample, $X_{p i}$ is the normalized processing data for the $i$-th variable of the pth sample. The preprocessed sample data range is $(0,1)$.

\subsection{Construction of fertilization model}

In order to achieve the target yield of corn, this paper establishes a RBF neural network model based on fusion algorithm, Study the best fertilization model of maize to achieve high yield of maize. Taking the soil nutrient content of Chenjiadian experiment field and the input as the neural network, the amount of fertilizer applied as the output of the neural network, In this paper, based on the RBF neural network fertilization model shown in Figure 4:

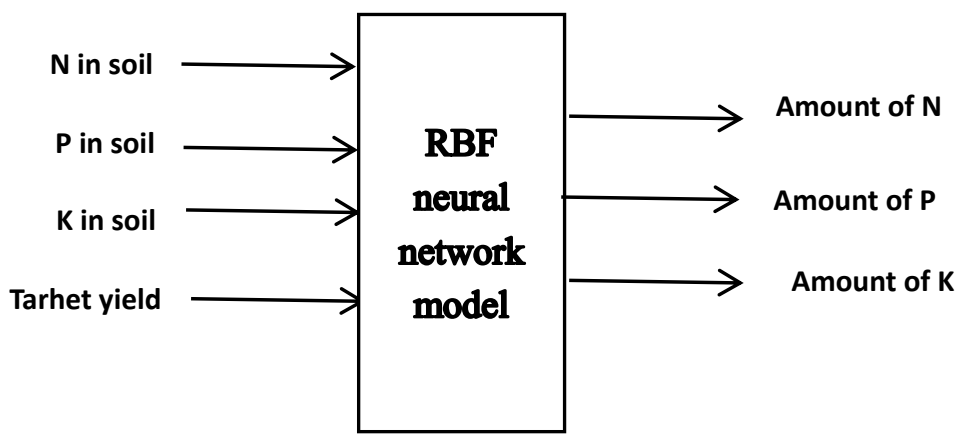

Figure 4: RBF neural network fertilization model

(1) different algorithms to predict performance comparison

In the training RBF network, the FCM algorithm, take $c=20$, in all the samples, through clustering, the first selected cluster center number 20 data centers; use OLS training RBF, take the error threshold of 0.01 to get regression Matrix information, On the basis of the initial selection of 20 centers, and then enter the choice, and finally get 10 effective data center. Using BP network, single RBF network and post-training RBF neural network (FCM-OLS-RBF) to test the sample, Test results are shown in Table 3:

Table 3: Comparison of different algorithms for prediction performance

\begin{tabular}{lccc}
\hline & BP & RBF & FCM-OLS-RBF \\
\hline TIME (s $)$ & 2.008 & 2.234 & 1.158 \\
MSE & 0.67115 & 0.243501 & 0.2 \\
\hline
\end{tabular}

It can be seen from Table 3 that from the prediction accuracy, the FCM-OLS-RBF model constructed in this paper has a prediction error of 0.2 , which is obviously better than RBF network and BP network. From the processing speed, FCM-OLS-RBF network is 1.93,1.73 times faster than single RBF network and BP neural network in predicting 10 samples. Thus, the RBF network after the improved algorithm has higher accuracy and faster speed than the single RBF network and the traditional BP network, and the practicability is stronger.

(2) FCM-OLS-RBF fusion algorithm simulation experiment

In this experiment, 64 samples of soil nutrient content, yield and actual fertilization amount in Chenjiadian and Kai'an were divided into three parts, Of which 44 samples were used as training set, 10 
samples were used as validation sets, and the remaining 10 samples were used as test sets. Before training RBF network, we first use FCM algorithm to select 20 centers in all training samples, then train the network with OLS, and finally select 10 centers. Finally, the trained RBF neural network was used to predict the soil fertilization amount of maize in the field of maize, Simulation results are shown in Figure 5:

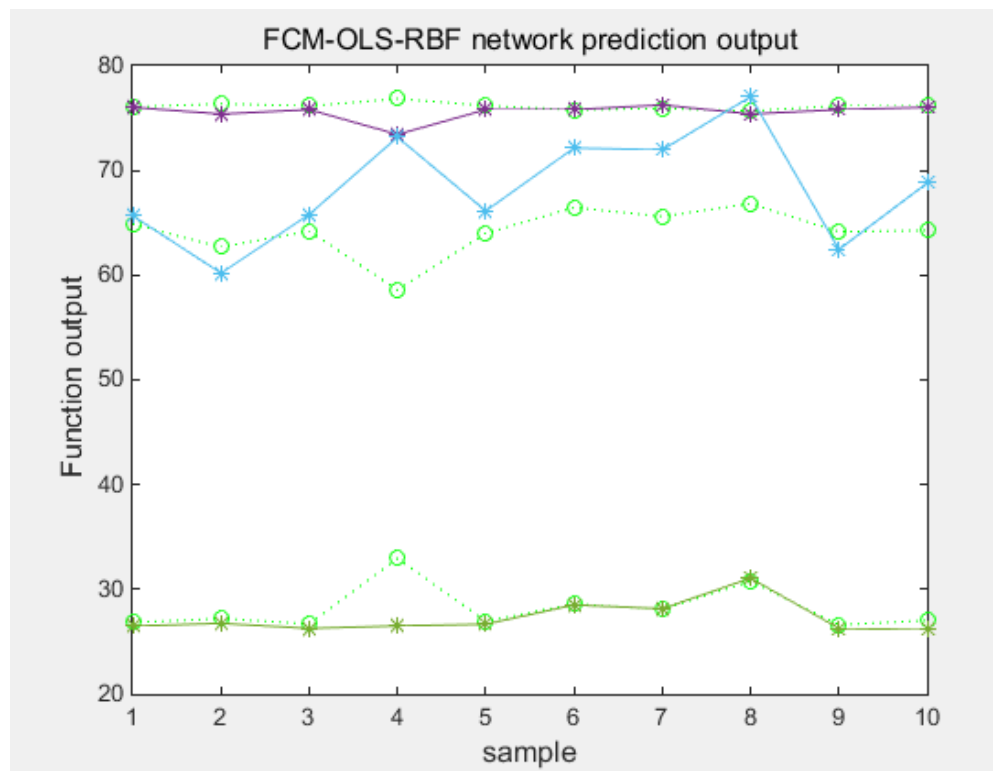

Figure 5: FCM-OLS-RBF network simulation results

It can be seen from Figure 5 that the predictive curve of FCM-OLS-RBF network is in good agreement with the measured curve, especially the predicted value and measured value of $N$ and $P$, and the deviation is very small, Showing its higher prediction accuracy.

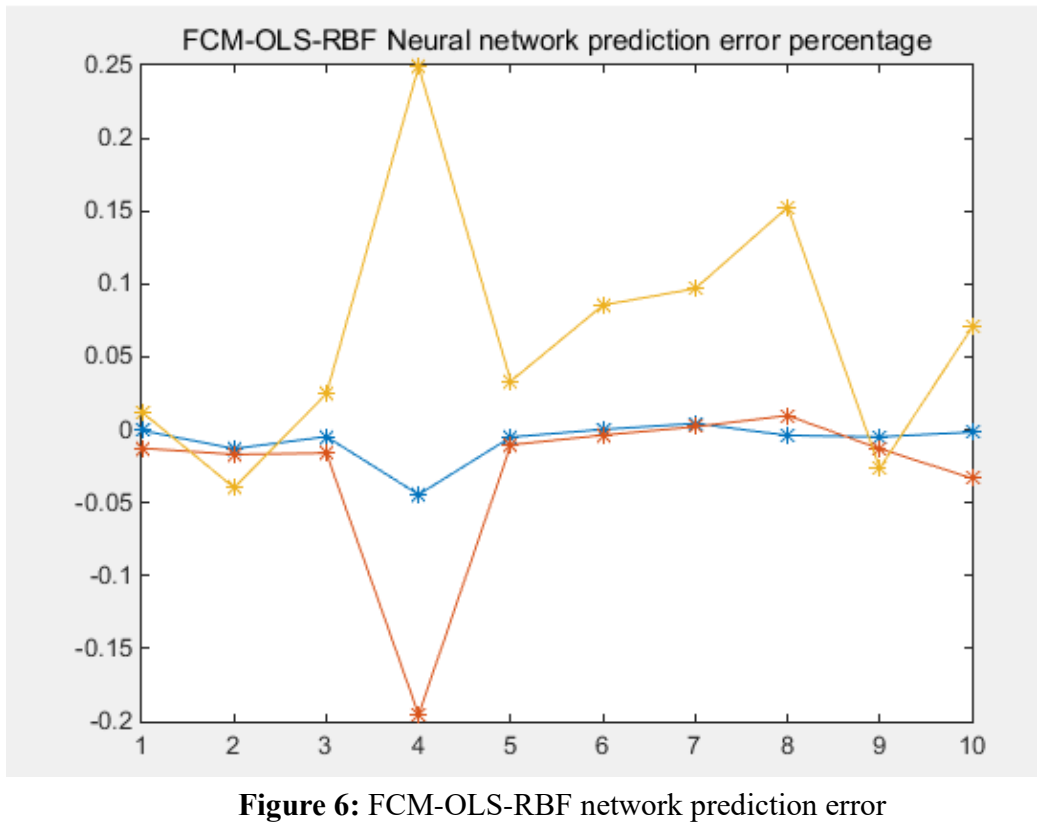

It can be seen from Fig. 6 that the relative error of nitrogen, phosphorus and potassium fertilizers is about $0.1 \%$, and the maximum error is below $0.25 \%$, which can meet the requirements of actual production. 


\section{Conclusion}

This paper focuses on the RBF neural network algorithm based on FCM clustering and OLS, and compares it with the traditional RBF and BP neural network. Finally, the method is applied to the precision fertilization problem. According to the experimental test, the following conclusions are drawn:

(1) FCM-OLS-RBF fertilization prediction model training speed, good convergence, In the case of large quantities of non-linear and accurate fertilization applications, Compared with the traditional RBF and BP network prediction results, it also shows its better evaluation accuracy. Both to ensure the accuracy of the network while simplifying the algorithm and network structure;

(2) The fertilization model based on FCM-OLS-RBF neural network can simulate the nonlinear relationship between soil test and fertilization, which is superior to the traditional fertilization model and can be used as a quantitative model to guide the accurate fertilization;

(3) A large number of training samples are needed to predict with a neural network, or the accuracy of prediction can not be accurately fitted due to the high degree of non-linear relationship between the factors and fertilization.

And because the factors affecting the amount of corn fertilization varied and intricate, the factors that affect the yield is not only the amount of fertilizer problems. In the future, with the deepening of the practice of variable fertilization, the accumulation of data is rich, can provide a broader basis for improving production.

\section{Acknowledgments}

This work was funded by National Spark Program "Based on the Internet of Things precise operation of corn technology integration and demonstration" (2015GA660004) 2015-2017

\section{Reference}

1. YANG Jian, LIU Xiao-xiao, FAN Hui-mei.Study on Nitrogen Fertilizer Effect of Different Types of Soils in Jilin Province[J]. Modern Agricultural Science and Technology, ,(18): 9-10 + 13. (2015)

2. XIE Jia-gui, WANG Li-chun, YIN Cai-xia, HOU Yun-peng, ZHANG Guo-hui, YU Lei.Study on Fertilization Effect of Different Types of Soils in Jilin Province [J]. Corn Science, (04): 167-171.( 2008)

3. Yu Helong, Liu Jie, Jin Di, Yang Yupeng, Liu Dawei.A new neural network ensemble method and its application in precision fertilization [J]. Computer Research and Development,(09): 1530-1538.( 2010)

4. Lan Weijuan, Mao Pengjun, Du Dongliang, Wang Jun.Study on variable fertilization decision based on radial basis function network [J]. Anhui Agricultural Sciences, (21): 6505-6507.( 2007)

5. Zhang Chang, Liang Yao, Ge Jiayao, Cai Hongguang, Yan Xiaogong, Liu Jianzhao, Yuan Jingchao, Zhang Hongxi, Ren Jun.Effects of $N, P, K$ and Potassium on Maize in Different Soil Types in the Central Jilin Province [J]. Northeast Agricultural Sciences, (04): 58-62.( 2016)

6. Li Zhixiang, Chen Zhijian. Slope stability evaluation method based on RBF-FCM-OLS [J]. Survey Science and Technology, (06): 1-4 + 17.( 2016)

7. Cui Guimei, et al.Study on prediction of blast furnace temperature by distributed RBF network model based on FCM [J]. Industrial Control Computer,(07): 1-2 + 5.( 2013)

8. Lei Shengkai, Liu Hongyang, He Jia, He Xianfeng, Xue Qin.Application of dynamic K - means clustering algorithm in RBF neural network center selection [J]. Information Systems Engineering,(06): 83-85.( 2011)

9. Hu J, Li D, Chen G, et al. Image segmentation method for crop nutrient deficiency based on fuzzy C-Means clustering algorithm[J]. Intelligent Automation \& Soft Computing, 18(8): 1145-1155.( 2012)

10. Si X, Peng Z, Yuan H, et al. Research on Cucumber Downy Mildew Images Classification Based on Fuzzy Pattern Recognition[J]. Sensor Letters,10(1-2): 643-648.( 2012)

11. SU Tieming, YE Sanqiu, SUN WeiAn thermal machine error compensation modeling based on FCM clustering and RBF neural network [J]. Combined machine tools and automated processing technology,(10): 1-4 +9.(2011)

12. Guan Shuo, Gao Junwei, Zhang Bin, Liu Xin, cold child.Based on K - means clustering algorithm RBF neural network traffic flow prediction [J]. Journal of Qingdao University (Engineering \& Technology Edition),(02): 20-23.(2014)

13. Chen Qiang, Zhang Junfeng, Wang Fei, Zheng Zhixiang.Optimal flight time prediction based on OLS-RBF neural 
network [J]. Aeronautical Computing Technology,(04): 42-45.( 2015)

14. Liu Jinling. Design and Implementation of RBF Network Based on OLS Algorithm [J] .Computer Age,(07): 21-22 + 25.(2010)

15. Chen Fei Xiang, Cheng Jiachang, Hu Yueming, Zhou Yongzhang, Zhao Yuan, ants good pureSpatial prediction of soil chromium content based on RBF neural network [J].Geography, (01): 69-74.(2013)

16. Wang Linbo.Study on tide level prediction of tidal reach based on improved OLS-RBF model [J]. Water Conservancy Planning and Design,(06): 51-54.( 2017)

17. LIN Fang.Application of gray neural network in grain yield prediction [J]. Computer Simulation,(04): 225-228 + 267.(2012)

18. [18] in the dragon, Zhao Xinzi, Chen Guifen, Wan Baocheng, Gao Jie.Based on the improved BP neural network integrated crop fertilization model [J]Journal of Agricultural Engineering,(12): 193-198.( 2010)

19. Jin Shuangzhen, Liu Guoshun, Yan Xinfu, Shi Hongzhi, Cheng Long. The necessity and application prospect of precision agriculture in China [J]. Journal of Zhejiang Agricultural Sciences,(02): 414-416.(2010)

20. Zhang Yaping, Song Beiguang, Wang Dongping, Yang Qingfeng, Dong Zhenfu. Effects of variable fertilization on maize yield traits [J]. Modern Agriculture,(11): 14-15.(2010)

21. Chen H, Cao L Y, Chen G. Research on the Evaluation and Forecast of Spatio-Temporal Variability of Soil Fertility in Black Soil Area of SongLiao Plain[J]. Sensor Letters,12(3-4): 743-748(2014) 